\title{
Comparison of safety, efficacy and perinatal outcome of isoxsuprine and nifedipine in women with preterm labour
}

\author{
Seema $\mathrm{BN}^{1 *}$, Tejaswi V. Pujar ${ }^{2}$
}

\begin{abstract}
${ }^{1}$ Department of Obstetrics and Gynaecology, Koppal Institute of Medical Sciences, Koppal, Karnataka, India ${ }^{2}$ Department of Obstetrics and Gynaecology, S S Institute of Medical Sciences and Research Centre, Davangere, Karnataka, India
\end{abstract}

Received: 19 December 2016

Accepted: 26 December 2016

\author{
*Correspondence: \\ Dr. Seema BN, \\ E-mail: drseemabn@gmail.com
}

Copyright: (c) the author(s), publisher and licensee Medip Academy. This is an open-access article distributed under the terms of the Creative Commons Attribution Non-Commercial License, which permits unrestricted non-commercial use, distribution, and reproduction in any medium, provided the original work is properly cited.

\begin{abstract}
Background: Over the last 50 years, extensive research has been conducted with the objective of preventing, predicting and optimizing the outcome of patients with preterm labour. Currently, the therapeutic foundation for treating preterm labour involves the use of tocolysis. An attempt is made to study the tocolytic effect of Isoxsuprine and nifedipine in suppression of preterm labour.

Methods: This is a prospective study, carried out in the department of Obstetrics and Gynaecology of S S institute of medical sciences and research centre, Davangere, over a period of 15 months- from October 2014 to January 2016.

Results: 60 antenatal cases with 28-36 weeks of gestation with painful intermittent uterine contractions were considered for the study. Subjects were randomly allotted into two groups - Group A (Isoxsuprine) and Group B (Nifedipine) 30 patients each. Main outcomes include prolongation of pregnancy, maternal side effects and neonatal outcome were compared. Baseline characteristics were well matched in both study groups. Mean prolongation of pregnancy was 31.68 days in Nifedipine and 27.54 days in Isoxsuprine group which was statistically significant. Success rate with Nifedipine was found to be $96 \%$ as compared to Isoxsuprine which was $75 \%$. Maternal side effects like hypotension $(13.33 \%)$ and tachycardia $(6.66 \%)$ were common in Isoxsuprine group, while facial flushing was seen in $16.66 \%$ patients in Nifedipine group. Neonatal outcome was similar in the both groups.

Conclusions: Nifedipine is a safe and effective tocolytic agent than Isoxsuprine with less maternal complications.
\end{abstract}

Keywords: Nifedipine, Preterm labour, Tocolysis

\section{INTRODUCTION}

Determination of efficacy and safety of tocolytic agents has been a difficult task because of various reasons. The cause of preterm labour is generally unknown. Therefore therapy cannot be directed to a specific cause. In about $30 \%$ of the patients with apparent preterm labour, uterine contractions cease spontaneously without treatment. Clinicians can never be sure which patient will progress in labour. There is lack of uniformity in the definition of preterm labour.

The diagnosis of preterm labour may be in error as much as $80 \%$ of the time. Also the criteria for success of tocolysis have been different by different authors. There are no accurate recent worldwide data but estimates of preterm birth range from a relative stable $5-10 \%$ in developed countries to as high as $25 \%$ in some of the worst hit developing countries. ${ }^{1}$ This prospective study was designed to find out the safety, efficacy and perinatal outcome of Isoxsuprine and Nifedipine in women with preterm labour.

\section{METHODS}

60 antenatal cases with $28-36$ weeks of gestation with painful intermittent uterine contractions are considered for the study. Sample size was based on the hospital 
statistics, exclusion criteria and non-cooperation of the patients. The subject was taken up for the study after taking informed consent and after satisfying the inclusion criteria's, after which they were randomly allotted into two groups - Group A (Isoxsuprine) and Group B (Nifedipine).

\section{Inclusion criteria}

- Gestational age between 28-36 weeks.

- About 1-2 regular uterine contractions occur in 10 min, each lasting for 30 seconds.

- Cervical effacement of more than $80 \%$ and with dilatation of less than $3 \mathrm{cms}$ with intact membranes.

- No previous administration of tocolytics.

\section{Exclusion criteria}

- Systemic diseases like diabetes mellitus, cardiac diseases, liver or renal diseases

- Obstetric complications like severe pregnancy induced hypertension, eclampsia, antepartum haemorrhage, hydramnios, hyperthyroidism

- Foetal complications like chorioamnionitis, IUGR, congenital anomaly, foetal distress, oligoamnios

- Multifoetal gestation

A detailed history, complete physical and obstetric examination and routine investigations were done for all the patients.

\section{Method of study}

Patients were taken up for the study after diagnosing preterm labour based on inclusion criteria. They are randomly allotted into two groups- Group A (Isoxsuprine) and Group B (Nifedipine).

\section{Treatment protocol}

\section{Isoxsuprine group}

Those patients assigned to Isoxsuprine group, started on Isoxsuprine infusion of $30-60 \mathrm{mg}$ in $500 \mathrm{ml}$ of $5 \%$ dextrose at $0.02 \mathrm{mg} / \mathrm{min}$, increasing the infusion rate up to $0.08 \mathrm{mg} / \mathrm{min}$, dose administration did not exceed 0.5 $\mathrm{mg} / \mathrm{min}$, depending on the status of uterine contractions and occurrence of side effects. After discontinuation of i.v infusion, patients maintained on oral Isoxsuprine 10 mg 8 hourly for up to 7 days.

\section{Nifedipine group}

Those assigned to Nifedipine group, received prehydration with intravenous infusion of ringer lactate at the rate of $100 \mathrm{ml} / \mathrm{hr}$, continued only till sublingual Nifedipine was administered. Nifedipine $10 \mathrm{mg}$ was given sublingually, and the same dose was repeated every 20 mins for up to 4 doses. 4-6 hrs after the last sublingual
Nifedipine dose, tablet Nifedipine 10-20 mg was given orally every 6-8 hrs, for not more than 7 days as a maintenance dose.

Patients in both groups were given antibiotics and injection betamethasone $24 \mathrm{mg}$ in 2 divided doses, $24 \mathrm{hrs}$ apart.

Uterine contractions, foetal heart rate and vital signs were monitored in both the study groups. Side effects are noted from the time of administration of drug till the patient was discharged from the labour ward.

Treatment was considered successful, if there was abolition of uterine contractions, no progression of cervical dilatation, and also if contractions did not recur with in $48 \mathrm{hrs}$ of cessation of therapy.

Treatment was deemed failure, despite maximal dose mentioned for both groups, if uterine relaxation was not achieved or patient or foetus developed some significant side effects that necessitated discontinuation of therapy.

Data regarding efficacy of the drugs in terms of arrest of preterm labour, prolongation of pregnancy and the days gained in utero were noted. Details of mode of delivery, gestational age at the time of delivery, baby's sex, birth weight and Apgar score were noted.

\section{RESULTS}

Majority of the patients in the present study were between 28-32 weeks of gestation ( $n=21$ vs 19) in Isoxsuprine group and Nifedipine group respectively. The mean gestational age in Isoxsuprine group and Nifedipine group is 31.62 weeks and 31.9 weeks respectively [Table1]. There is no statistically significant difference in both study groups with respect to gestational age. In the present study, primigravidae were more in Isoxsuprine group $(n=17)$ as compared to Nifedipine group $(n=14)$.

Commonest and most significant risk factor in Isoxsuprine and Nifedipine groups was anaemia ( $n=16$ vs 19 respectively), followed by substance abuse (tobacco $\mathrm{n}=13$ vs 10 ), physical and psychological stress ( $\mathrm{n}=11$ vs $15)$ and infections ( $n=6$ vs 4 ).

In our study, prolongation of pregnancy was more in Nifedipine group 31.68 days when compared to Isoxsuprine group 27.54 days. The prolongation is statistically significant $\mathrm{P}$ being $\leq 0.001$ and it depended on the gestational age at the onset of tocolytic therapy and the time from the onset of therapy to delivery.

Period of gestation at the time of delivery was $\geq 37$ weeks in 20 of cases in Nifedipine group when compared to Isoxsuprine group (14). 06 patients in Isoxsuprine and 05 patients in Nifedipine group have lost to follow up. 
Table 1: Baseline characteristics of the study population.

\begin{tabular}{|c|c|c|}
\hline & $\begin{array}{l}\text { Group A } \\
\text { No. of } \\
\text { patients } \\
(\mathbf{n}=\mathbf{3 0})\end{array}$ & $\begin{array}{l}\text { Group B } \\
\text { No. of } \\
\text { patients } \\
(\mathbf{n}=\mathbf{3 0})\end{array}$ \\
\hline \multicolumn{3}{|c|}{ Gestational age (weeks) } \\
\hline $28-30$ & 08 & 09 \\
\hline $31-32$ & 13 & 10 \\
\hline $33-36$ & 09 & 11 \\
\hline \multicolumn{3}{|l|}{ Parity } \\
\hline Nulliparous & 17 & 14 \\
\hline Multiparous & 13 & 16 \\
\hline \multicolumn{3}{|c|}{ Risk factors for preterm delivery } \\
\hline Previous preterm & 01 & 03 \\
\hline Abortions & 04 & 07 \\
\hline Evidence of infection & 06 & 04 \\
\hline Previous D and E & 04 & 04 \\
\hline $\begin{array}{l}\text { Physical and } \\
\text { psychological stress }\end{array}$ & 11 & 15 \\
\hline $\begin{array}{l}\text { Coitus during } \\
\text { pregnancy }\end{array}$ & 01 & 02 \\
\hline Substance abuse & 13 & 10 \\
\hline Anaemia & 16 & 19 \\
\hline No risk factor found & 11 & 10 \\
\hline \multicolumn{3}{|c|}{ Prolongation of pregnancy (days) } \\
\hline Mean & 27.54 & 31.68 \\
\hline \multicolumn{3}{|c|}{ Gestational age at delivery (weeks) } \\
\hline$<37$ & 10 & 05 \\
\hline$\geq 37$ & 14 & 20 \\
\hline Lost to follow up & 06 & 05 \\
\hline \multicolumn{3}{|l|}{ Perinatal outcome } \\
\hline Birth weight- mean & 1.94 & 2.06 \\
\hline Apgar score at $1 ",<7$ & 14 & 4 \\
\hline$>7$ & 10 & 21 \\
\hline \multicolumn{3}{|l|}{ Maternal side effects } \\
\hline Tachycardia $\geq 110 \mathrm{bpm}$ & 02 & 01 \\
\hline Headache & 00 & 00 \\
\hline Hypotension $<90 / 60$ & 04 & 00 \\
\hline Facial flushing & 00 & 05 \\
\hline \multicolumn{3}{|l|}{ Treatment response } \\
\hline Success & 18 & 24 \\
\hline Failure & 06 & 01 \\
\hline
\end{tabular}

In the present study, mean birth weight of infants delivered is $2.06 \mathrm{kgs}$ in Nifedipine group with apgar scores of $>7$ at 1 ' are seen 21 cases. In Isoxsuprine group, infants delivered had mean birth weight of $1.94 \mathrm{kgs}$ with Apgar scores of $>7$ at 1 ' are 10 cases.

In our study, hypotension was noted in 04 patients of Isoxsuprine group as compared to Nifedipine group where none of them had hypotension, while other side effects like facial flushing noted in 5 patients of Nifedipine group and tachycardia in 2 patients of Isoxsuprine and 1 patient of Nifedipine group. No other serious side effects noted in both groups. In our study Nifedipine group has highest success rate compared to Isoxsuprine group.

\section{DISCUSSION}

Prematurity continues to be the major contributor to the perinatal morbidity and mortality. The approaches which prevent and treat preterm labour will have great impact on society and long term public health care costs. None of the currently available tocolytic agents are ideal. Calcium channel blockers are safer and more effective than betamimetics. The measures taken to prolong pregnancy have shown to reduce neonatal morbidity and mortality.

This prospective study was designed to find out the safety, efficacy and perinatal outcome of Isoxsuprine and Nifedipine in women with preterm labour. Patients were included into the study group in which uterine contractions continued even after complete bed rest. This could reduce the number of patients in false labour being included in the study.Since the late 1970's Nifedipine has been known to relax the pregnant and non-pregnant uterus (Ulmsten, Anderson KE). ${ }^{2}$

The patients in both groups were well matched regarding age, antenatal care, gravidity, previous obstetric history and socio economic status. This is supported by wellmatched randomised controlled trials conducted by Kedar MG et al, Kalita D et al, Rayamajhi R et al, Singh N. ${ }^{3-6}$

Most of the studies so far conducted have compared the efficacy and safety between Nifedipine and Ritodrine. Only few studies have been done between Nifedine and Isoxsuprine. Kedar MG et al, Kalita D et al, Rayamajhi R et al, Singh $N$ have conducted studies about comparison between the efficacy and safety of Nifedipine and Isoxsuprine in the suppression of preterm labour. ${ }^{3-6}$

The mean prolongation of pregnancy in the present study was $31.68 \pm 8.37$ days with Nifedipine and $27.54 \pm 7.38$ days with Isoxsuprine. These results were similar to those reported by Kalita D et al study. ${ }^{4}$ Kalita et al reported mean prolongation of pregnancy as $31.16 \pm 10.2$ days with Nifedipine and 23.06 days with Isoxsuprine. ${ }^{4}$ Kedar et $\mathrm{al}^{3}$ reported mean prolongation of pregnancy as $22.4 \pm$ 15.6 days with Nifedipine and $16.5 \pm 14.5$ days

with Isoxsuprine. Rayamajhi et al reported mean prolongation of pregnancy as 25.71 days with Nifedipine and 19.18 days with Isoxsuprine. ${ }^{5}$ Tewari et al reported mean prolongation of pregnancy as $39.26 \pm 25.5$ days with Nifedipine and $25.5 \pm 15.75$ days with Isoxsuprine. ${ }^{7}$ Indian study conducted by Singh S and Gupta K observed that prolongation of pregnancy was more when the period of gestation was less, being 47.44 days at 22-24 weeks and only 10.18 days at 33-36 weeks of gestation. ${ }^{8}$ We infer that prolongation of pregnancy depends not only on 
the gestational age at the time of tocolysis, duration of tocolysis but also the dose given for tocolysis.

In the present study, successful tocolysis was achieved in $96 \%$ with Nifedipine group and $75 \%$ with Isoxsuprine group. These results were similar to those reported by Kedar et al, $88 \%$ with Nifedipine and $76 \%$ with Isoxsuprine group. ${ }^{3}$ Rayamajhi et al reported $81.25 \%$ successful tocolysis with Nifedipine and $70 \%$ with Isoxsuprine group. ${ }^{5}$

The maternal side effects observed in our study were less as compared to Kedar et al and Rayamajhi et al study.,5 No significant change in blood pressure was observed with Nifedipine group in our study that necessitated discontinuation of therapy, as Nifedipine exhibits greater selectivity for inhibition of uterine activity relative to cardiovascular effects. This may be attributed to the use of prehydration in the nifedipine regime.

\section{CONCLUSION}

Preterm labour and delivery remains a major cause of perinatal morbidity and mortality. Tocolytic agents are currently the principal preterm birth preventive measure and will remain so until the aetiology of preterm labour is better understood. Calcium channel blockers (nifedipine) are safer and more effective in suppressing preterm labour.

\section{Funding: No funding sources} Conflict of interest: None declared

Ethical approval: The study was approved by the Institutional Ethics Committee

\section{REFERENCES}

1. PJ Steers. The Epidemiology of preterm labour. Br J Obstet Gynecol. 2005;112(Suppl.1):1-3.

2. Singh N, Singh U, Seth S. Comparative study of Nifedipine and isoxsuprine as tocolytics for preterm labour. The Journal of Obstetrics and Gynecology of India. 2011:61(5):512-5.

3. Ulmsten U, Anderson KR, Hingerup L. Treatment of preterm labour with the calcium antagonist nifedipine. Arch Gynecol. 1980;229:1-5.

4. Ganla KM, Shroff SA, Desail S. A prospective comparative of Nifedipine and Isoxsuprine for tocolysis. Bombay Hospital Journal. 1999;259.

5. Kalita D, Goswami A, Muzumatar KL. A comparative study of Nifedipine and Isoxsuprine hydrochloride in the management of preterm labour. J Obstet Gynecol India. 1998;48:47-50.

6. Rayamajhi R, Pratap K. A comparative study between Nifedipine and Isoxsuprine in the suppression of preterm labour. Kathmandu University Medical Journal. 2003;1(2):85-90.

7. Tewari S, Sachan A, Gulati N. Nifedipine, a safer alternative tocolytic in preterm labour. The Indian Practitioner. 1997;50:307-10.

8. Singh S, Gupta K, Ahluwalia G. Role of nifedipine in preterm labour and its effect on perinatal outcome. J Obstet Gynecol India. 1992:687-693.

Cite this article as: Seema BN, Pujar TV.

Comparison of safety, efficacy and perinatal outcome of isoxsuprine and nifedipine in women with preterm labour. Int J Reprod Contracept Obstet Gynecol 2017;6:400-3. 